\title{
Assessment of Factors Related to Auto-PEEP
}

\author{
Giuseppe Natalini MD, Daniele Tuzzo MD, Antonio Rosano MD, Marco Testa MD, \\ Michele Grazioli MD, Vincenzo Pennestrì MD, Guido Amodeo MD, Paolo F Marsilia MD, \\ Andrea Tinnirello MD, Francesco Berruto MD, Marialinda Fiorillo MD, Matteo Filippini MD, \\ Alberto Peratoner MD, Cosetta Minelli MD PhD, and Achille Bernardini MD; on behalf of the \\ VENTILAB Group
}

\begin{abstract}
BACKGROUND: Previous physiological studies have identified factors that are involved in autoPEEP generation. In our study, we examined how much auto-PEEP is generated from factors that are involved in its development. METHODS: One hundred eighty-six subjects undergoing controlled mechanical ventilation with persistent expiratory flow at the beginning of each inspiration were enrolled in the study. Volume-controlled continuous mandatory ventilation with PEEP of 0 cm $\mathrm{H}_{2} \mathrm{O}$ was applied while maintaining the ventilator setting as chosen by the attending physician. End-expiratory and end-inspiratory airway occlusion maneuvers were performed to calculate respiratory mechanics, and tidal flow limitation was assessed by a maneuver of manual compression of the abdomen. RESULTS: The variable with the strongest effect on auto-PEEP was flow limitation, which was associated with an increase of $2.4 \mathrm{~cm} \mathrm{H}_{2} \mathrm{O}$ in auto-PEEP values. Moreover, autoPEEP values were directly related to resistance of the respiratory system and body mass index and inversely related to expiratory time/time constant. Variables that were associated with the breathing pattern (tidal volume, frequency minute ventilation, and expiratory time) did not show any relationship with auto-PEEP values. The risk of auto-PEEP $\geq 5 \mathrm{~cm} \mathrm{H}_{2} \mathrm{O}$ was increased by flow limitation (adjusted odds ratio 17; 95\% CI: 6-56.2), expiratory time/time constant ratio $<1.85$ (12.6; 4.7-39.6), respiratory system resistance $>15 \mathrm{~cm} \mathrm{H}_{2} \mathrm{O} / \mathrm{L} \mathrm{s}(3 ; 1.3-6.9)$, age >65 y (2.8; $1.2-6.5)$, and body mass index $>26 \mathrm{~kg} / \mathrm{m}^{2}(2.6 ; 1.1-6.1)$. CONCLUSIONS: Flow limitation, expiratory time/time constant, resistance of the respiratory system, and obesity are the most important variables that affect auto-PEEP values. Frequency expiratory time, tidal volume, and minute ventilation were not independently associated with auto-PEEP. Therapeutic strategies aimed at reducing auto-PEEP and its adverse effects should be primarily oriented to the variables that mainly affect auto-PEEP values. Key words: respiration; artificial; positive-pressure respiration; intrinsic; respiratory function tests; respiratory mechanics; respiratory physiological phenomena; respiratory insufficiency. [Respir Care 2016;61(2):134-141. (C) 2016 Daedalus Enterprises]
\end{abstract}

\section{Introduction}

Dynamic hyperinflation is defined as an increase in endexpiratory lung volume that is sustained by incomplete

Drs Natalini, Rosano, Grazioli, and Bernardini are affiliated with the Department of Anesthesia and Intensive Care, Fondazione Poliambulanza Hospital, Brescia, Italy. Dr Tuzzo is affiliated with the Department of Anesthesia and Intensive Care, Spedali Civili Hospital, Brescia, Italy. Dr Testa is affiliated with the Department of Anesthesia and Intensive Care, SS Annunziata Hospital, Savigliano, Italy. Dr Pennestri is affiliated with the Department of Anesthesia and Intensive Care, Misericordia expiration. Dynamic hyperinflation is associated with alveolar, autogenerated PEEP, which is termed auto-PEEP, intrinsic PEEP, or occult PEEP. ${ }^{1}$ Auto-PEEP and dynamic

\footnotetext{
Hospital, Grosseto, Italy. Dr Amodeo is affiliated with the Department of Anesthesia and Intensive Care, San Giovanni Bosco Hospital, Napoli, Italy. Dr Marsilia is affiliated with the Department of Anesthesia and Intensive Care, Cardarelli Hospital, Napoli, Italy. Dr Tinnirello is affiliated with the Department of Anesthesia and Intensive Care, Mellino Mellini Hospital, Chiari, Italy. Dr Berruto is affiliated with the Department of Anesthesia and Intensive Care, Agnelli Hospital, Pinerolo, Italy. Dr Fiorillo is affiliated with the Department of Anesthesia and Intensive
} 
hyperinflation may have detrimental effects on respiratory and cardiovascular function. They can reduce cardiac output and arterial pressure, predispose to ventilator-induced lung injury, increase work of breathing, worsen efficiency of the respiratory muscles, and induce patient-ventilator asynchrony. ${ }^{1-8}$

\section{See the Related Editorial on Page 258}

Several pathophysiological and clinical conditions that determine dynamic hyperinflation and auto-PEEP have been well described over the last 30 years. These conditions include increased airway resistance, a short expiratory time $\left(\mathrm{T}_{\mathrm{E}}\right)$, a long time constant of the respiratory system $\left(\tau_{\mathrm{RS}}\right)$, high minute ventilation, tidal expiratory flow limitation, chronic pulmonary disease, acute respiratory failure, and obesity. ${ }^{1,8-13}$ Despite the known role of these causes, the quantitative effects on auto-PEEP values are unknown. Therefore, the contribution of each of the determinants of auto-PEEP is unknown, as well as which of them are associated with the risk of high auto-PEEP levels.

Knowledge of the quantitative weight of the different possible causes of auto-PEEP could have some useful practical implications. First, patients with high auto-PEEP values could be more easily identified, even when end-expiratory occlusion maneuvers are not reliable or suitable. Second, the most effective approach could be chosen to reduce auto-PEEP and its adverse effects if interventions are targeted mainly toward the factors that have the most relevant effect on auto-PEEP levels.

Therefore, this study aimed to investigate the contribution of factors involved in auto-PEEP generation. Moreover, we aimed to identify the variables that are independently associated with high values of auto-PEEP in mechanically ventilated subjects with incomplete expiration.

\footnotetext{
Care, Santa Maria degli Angeli Hospital, Pordenone, Italy. Dr Filippini is affiliated with the Department of Anesthesia, Critical Care Medicine, and Emergency, University of Brescia at Spedali Civili, Brescia, Italy. Dr Peratoner is affiliated with the Department of Anesthesia and Intensive Care, Cattinara Hospital, Trieste, Italy. Dr Minelli is affiliated with Respiratory Epidemiology, Occupational Medicine \& Public Health, Imperial College, London, United Kingdom. See the complete list of VENTILAB Group members below.
}

This study was provided by institutional departmental funds. The authors have disclosed no conflicts of interest.

Correspondence: Giuseppe Natalini MD, Department of Anesthesia and Intensive Care, Fondazione Poliambulanza Hospital, via Bissolati 57, Brescia, Italy 25124. E-mail: giuseppe.natalini@gmail.com.

DOI: $10.4187 /$ respcare.04063

\section{QUICK LOOK}

\section{Current knowledge}

Dynamic hyperinflation is defined as an increase in end-expiratory lung volume sustained by incomplete expiration. Dynamic hyperinflation is associated with alveolar, auto-generated PEEP. Auto-PEEP and dynamic hyperinflation can reduce cardiac output and arterial pressure, predispose to ventilator-induced lung injury, increase work of breathing, worsen respiratory muscle efficiency, and induce patient-ventilator asynchrony. Clinical conditions that determine dynamic hyperinflation and auto-PEEP include increased airway resistance, a short expiratory time, a long time constant of the respiratory system, high minute ventilation, and tidal expiratory flow limitation.

\section{What this paper contributes to our knowledge}

In mechanically ventilated subjects with dynamic hyperinflation, the amount of auto-PEEP mainly depends on expiratory flow limitation, a long time constant of the respiratory system compared with the available expiratory time, high resistance of the respiratory system, and obesity. Therapeutic strategies aimed at reducing auto-PEEP and its adverse effects should be primarily oriented to these targets.

\section{Methods}

In this cross-sectional study, we enrolled mechanically ventilated subjects with evidence of incomplete expiration and absence of spontaneous respiratory activity. The study was conducted in a network of Italian intensive care units from January to June 2013. The protocol was approved by the institutional ethics committee, and informed consent was obtained by subjects or their next of kin, as appropriate.

Subjects were recruited if they met all of the following criteria: (1) tracheal intubation (or tracheotomy) and controlled mechanical ventilation; (2) absence of any sign of spontaneous respiratory activity (absence of triggering, passive inspiration, and passive expiration as evaluated by airway pressure and air flow waveforms); and (3) persistence of expiratory flow at the beginning of each inspiration. Exclusion criteria were an age of $<18 \mathrm{y}$, contraindication to compression of the abdomen (ie, pregnancy, recent abdominal surgery, and abdominal aortic aneurysm), cardiovascular instability (mean arterial pressure $<60 \mathrm{~mm}$ $\mathrm{Hg}$, systolic arterial pressure $>180 \mathrm{~mm} \mathrm{Hg}$, heart rate $<40 /$ min or $>150 / \mathrm{min}$ ), severe hypoxemia $\left(\mathrm{S}_{\mathrm{aO}_{2}}<90 \%\right)$, and intracranial hypertension (intracranial pressure $>20 \mathrm{~mm} \mathrm{Hg}$ ). For study enrollment, the investigators 
screened all subjects present in the ICU during their working time.

The following data were collected at enrollment: diagnosis at admission, sex, age, body mass index (BMI), diagnosis of chronic or acute pulmonary disease, $\mathrm{P}_{\mathrm{aCO}_{2}}$ and $\mathrm{pH}$ at the moment of tracheal intubation, history of smoking, the Simplified Acute Physiology Score II, the Sequential Organ Failure Assessment score on the day of the study, body position during the study, tidal volume $\left(\mathrm{V}_{\mathrm{T}}\right)$, breathing frequency $(\mathrm{f})$, inspiratory time $\left(\mathrm{T}_{\mathrm{I}}\right), \mathrm{T}_{\mathrm{E}}$, PEEP, and $\mathrm{P}_{\mathrm{aO}_{2}} / \mathrm{F}_{\mathrm{IO}_{2}}$. The study subjects were ventilated with a Servo-i (Maquet, Solna, Sweden), Evita XL or Evita 4 (Dräger, Lübeck, Germany), or Engstroem Carestation (GE Healthcare, Helsinki, Finland) ventilator.

\section{Protocol}

After enrollment, subjects received volume-controlled continuous mandatory ventilation with constant inspiratory flow while maintaining $\mathrm{V}_{\mathrm{T}}$, $\mathrm{f}$, and $\mathrm{T}_{\mathrm{I}}$ as set by the attending physician. The mechanical ventilator settings were decided for each subject according to clinical requirements. The average ventilator setting was: $\mathrm{V}_{\mathrm{T}}=$ $503 \pm 64 \mathrm{~mL}, \mathrm{f}=19 \pm 4 \mathrm{~min}^{-1}, \mathrm{~T}_{\mathrm{I}} /$ time of respiratory cycle $=0.43 \pm 0.1$, PEEP $=6 \pm 2 \mathrm{~cm} \mathrm{H}_{2} \mathrm{O}$, and $\mathrm{F}_{\mathrm{IO}_{2}}=$ $0.48 \pm 0.13$. PEEP was set at $0 \mathrm{~cm} \mathrm{H}_{2} \mathrm{O}$. Three endexpiratory and 3 end-inspiratory occlusion maneuvers, each lasting $4 \mathrm{~s}$, were then performed with at least 10 uninterrupted breaths between the occlusion maneuvers. During each occlusion maneuver, the following measurements were taken: peak airway pressure, end-inspiratory plateau pressure, end-expiratory plateau pressure (ie, auto-PEEP), $\mathrm{V}_{\mathrm{T}}$, and inspiratory flow. The mean value of each variable was used for subsequent analysis and calculation. Compliance of the respiratory system $\left(\mathrm{C}_{\mathrm{RS}}\right)$ was calculated as $\mathrm{V}_{\mathrm{T}}$ /(end-inspiratory plateau pressure - auto-PEEP) and resistance of the respiratory system $\left(R_{R S}\right)$ as (peak airway pressure - end-inspiratory plateau pressure)/inspiratory flow. The $\tau_{\mathrm{RS}}$ was calculated as the product of $\mathrm{R}_{\mathrm{RS}}$ and $\mathrm{C}_{\mathrm{RS}} \cdot{ }^{14}$

After the occlusion maneuvers, the presence of flow limitation was assessed with manual compression of the abdomen. ${ }^{15-17}$ Briefly, the investigator put one hand gently on the abdominal wall of the subject with the palm on the umbilicus oriented perpendicularly to the axis between the xiphoid process and the pubis. After a short period, which allowed for recognition of the expiratory phase, the investigator exerted firm but gentle compression of the abdomen in an antero-posterior direction as soon as the insufflation was finished. This compression was maintained throughout expiration. The flow-volume loops obtained during passive expiration and during the manual compression of the abdominal maneuver were superimposed. flow limitation was diagnosed when all or part of the expiratory flow during the manual compression of the abdominal maneuver and passive expiration were superimposed on the flow-volume loops. However, if during the manual compression of the abdominal maneuver the expiratory flow at any volume was higher than under passive conditions, the subject was classified as having no flow limitation. Three maneuvers were performed, and subjects were classified as flow-limited if flow limitation was consistently confirmed in all of the 3 maneuvers. Subjects were dropped from the study if they showed any spontaneous respiratory activity, severe hypoxemia, or cardiovascular instability, as previously defined, at any time during the study.

\section{Data Validation}

Each enrolled subject was analyzed for reliability of measurements and absence of spontaneous respiratory activity. Data were considered reliable if the difference between each of the 3 measurements and their average value was $\leq 10 \%$ (a difference of $1 \mathrm{~cm} \mathrm{H}_{2} \mathrm{O}$ was tolerated) for each variable measured in airway pressure. Furthermore, the investigators took images of airway and flow waveforms during basal ventilation and end-inspiratory and endexpiratory occlusions and of the superimposed flow-volume loops obtained during the manual compression of the abdominal maneuver and during passive expiration. These images were assessed and discussed by 4 senior authors (GN, DT, AK, and MT), who had to confirm the absence of any sign of respiratory activity and the diagnosis of flow limitation. Only data from subjects with valid data were included in the analysis.

\section{Outcomes}

Auto-PEEP values were the study outcome, and the following explanatory variables involved in auto-PEEP were considered: sex, age, history of smoking, diagnosis of chronic pulmonary disease (defined as a previous diagnosis of chronic obstructive pulmonary disease, chronic bronchitis, or emphysema), $\mathrm{P}_{\mathrm{aO}_{2}} / \mathrm{F}_{\mathrm{IO}_{2}}$ ratio, the need for intubation because of hypercapnic respiratory failure $(\mathrm{pH}$ $<7.35$ and $\mathrm{P}_{\mathrm{aCO}_{2}}>45 \mathrm{~mm} \mathrm{Hg}$ at tracheal intubation), flow limitation, $B M I, R_{R S}, C_{R S}, T_{E}, T_{E} / \tau_{R S}, V_{T} / k g$ of ideal body weight, $\mathrm{f}$, minute ventilation, and body position (supine or semi-recumbent).

\section{Sample Size}

At least 10 events per variable should be analyzed in logistic regression to guarantee accuracy and precision of regression coefficients. ${ }^{18}$ Therefore, we anticipated enrollment of at least 170 valid subjects because we planned to test 17 possible explanatory variables. 


\section{Assessment of Factors Related to Auto-PEEP}

\section{Statistical Analysis}

Data are shown as mean $\pm \mathrm{SD}$, median (interquartile range), or $n$ (percentage) as appropriate. The association of the study variables with auto-PEEP (main study outcome) was assessed with multiple linear regression. The initial model included all variables with a $P$ value of $<.1$ in univariate analysis, and the final model was obtained through a backward stepwise procedure. At each step, the variable with the largest $P$ value was deleted, and the new model was compared with the previous one using the Akaike information criterion. Multicollinearity in the regression models was assessed by the variance inflation factor.

We also evaluated the association of the study variables with the presence of high auto-PEEP, defined as autoPEEP of $\geq 5 \mathrm{~cm} \mathrm{H}_{2} \mathrm{O}$. This threshold value does not have a specific pathophysiological meaning and was chosen only because it split subjects into 2 groups. The differences between high and low auto-PEEP groups for all study variables were analyzed with a chi-squared test, Fisher exact test, $t$ test, or Wilcoxon test, as appropriate. A multiple logistic regression analysis was performed to obtain estimates of the effects, expressed as odds ratios with $95 \%$ CI, adjusted for one another. The multiple logistic regression model was developed using the same approach as for the multiple linear regression analysis (variables with univariate $P$ value $<.1$ included in the initial model and backward stepwise procedure used to select the variable for the final model).

All $P$ values $<.05$ were considered significant. Statistical analysis was performed using the statistical software R 3.0.1 (R Foundation for Statistical Computing, Vienna, Austria).

\section{Results}

One hundred eighty-six subjects met the criteria for data validation and were included in the analysis. The mean auto-PEEP was $5 \pm 3 \mathrm{~cm} \mathrm{H}_{2} \mathrm{O}$, and the characteristics of the study population are shown in Table 1 .

Multiple linear regression analysis showed that flow limitation, $\mathrm{T}_{\mathrm{E}} / \tau_{\mathrm{RS}}, \mathrm{R}_{\mathrm{RS}}$, and $\mathrm{BMI}$ were independently associated with auto-PEEP levels (Table 2). The coefficient of flow limitation was 2.4 , which indicated that the presence of flow limitation was associated with an increase of 2.4 in auto-PEEP values. $\mathrm{T}_{\mathrm{E}}$ showed no relationship with auto-PEEP values, but a strong inverse relationship became evident when $\mathrm{T}_{\mathrm{E}}$ was normalized to $\tau_{\mathrm{RS}}$. Our data indicated a reduction in auto-PEEP of $0.7 \mathrm{~cm} \mathrm{H}_{2} \mathrm{O}$ per unit increase in the $\mathrm{T}_{\mathrm{E}} / \tau_{\mathrm{RS}}$ ratio (ie, the longer the $\mathrm{T}_{\mathrm{E}} / \tau_{\mathrm{RS}}$, the lower the auto-PEEP). The coefficients of BMI and $R_{R S}$ were 0.08 and 0.07 , respectively. These findings indicated that an increase of $10 \mathrm{~kg} / \mathrm{m}^{2}$ in BMI was associated with an increase of $0.8 \mathrm{~cm} \mathrm{H}_{2} \mathrm{O}$ in auto-PEEP, whereas an increase of $10 \mathrm{~cm} \mathrm{H}_{2} \mathrm{O} / \mathrm{L} / \mathrm{s}$ of $\mathrm{R}_{\mathrm{RS}}$ was associated with an increase of $0.7 \mathrm{~cm} \mathrm{H}_{2} \mathrm{O}$ in auto-PEEP.
Table 1. Subjects' Characteristics

\begin{tabular}{|c|c|}
\hline Characteristic & Values \\
\hline Age, y & $71(61-77)$ \\
\hline Female sex, $n(\%)$ & $63(34)$ \\
\hline History of smoking, $n(\%)$ & $82(49)$ \\
\hline Chronic pulmonary disease, $n(\%)$ & $64(35)$ \\
\hline Body mass index $\left(\mathrm{kg} / \mathrm{m}^{2}\right)$ & $27(24-29)$ \\
\hline \multicolumn{2}{|l|}{ Admission diagnosis in ICU, $n(\%)$} \\
\hline Respiratory & $67(36)$ \\
\hline Neurological & $41(22)$ \\
\hline Cardiovascular & $22(12)$ \\
\hline Trauma & $20(11)$ \\
\hline Surgery & $7(4)$ \\
\hline Other & $28(15)$ \\
\hline Hypercapnic respiratory failure, $n(\%)$ & $48(26)$ \\
\hline SAPS II & $50(40-60)$ \\
\hline SOFA & $8(5-9)$ \\
\hline Expiratory tidal flow limitation, $n(\%)$ & $75(40)$ \\
\hline Breathing frequency, breaths/min & $20(16-22)$ \\
\hline Expiratory time, s & $1.6(1.3-2.5)$ \\
\hline Tidal volume/ideal body weight, $\mathrm{mL} / \mathrm{kg}$ & $8(7-9)$ \\
\hline Minute ventilation, $\mathrm{L} / \mathrm{min}$ & $9.6 \pm 2.2$ \\
\hline $\mathrm{R}_{\mathrm{RS}}, \mathrm{cm} \mathrm{H}_{2} \mathrm{O} / \mathrm{L} / \mathrm{s}$ & $16(13-21)$ \\
\hline Compliance respiratory system, $\mathrm{mL} / \mathrm{cm} \mathrm{H}_{2} \mathrm{O}$ & $55(45-71)$ \\
\hline Time constant, s & $0.9(0.7-1.2)$ \\
\hline PEEP, $\mathrm{cm} \mathrm{H}_{2} \mathrm{O}$ & $6(5-8)$ \\
\hline $\mathrm{pH}$ & $7.39(7.29-7.45)$ \\
\hline $\mathrm{P}_{\mathrm{aCO}_{2}}, \mathrm{~mm} \mathrm{Hg}$ & $42(36-56)$ \\
\hline $\mathrm{P}_{\mathrm{aO}_{2}} / \mathrm{F}_{\mathrm{IO}_{2}}, \mathrm{~mm} \mathrm{Hg}$ & 232 (174-333) \\
\hline \multicolumn{2}{|c|}{$\begin{array}{l}\text { Data are shown as mean } \pm \text { SD, median (interquartile range), or } n(\%) \text { as appropriate. } \\
\text { SAPS = Simplified Acute Physiology Score } \\
\text { SOFA = Sequential Organ Failure Assessment } \\
R_{\mathrm{RS}}=\text { resistance of the respiratory system }\end{array}$} \\
\hline
\end{tabular}

Table 2. Multiple Linear Regression of the Relationships Between Auto-PEEP and Explanatory Variables

\begin{tabular}{lcc}
\hline \hline & Coefficient (95\% CI) & $P$ \\
\hline Flow limitation & $2.4(1.6-3.2)$ & $<.001$ \\
Expiratory time/time constant & $-0.7(-1$ to -0.4$)$ & $<.001$ \\
Body mass index & $0.08(0.02-0.15)$ & .007 \\
Resistance of the respiratory system & $0.07(0.02-0.13)$ & .01 \\
\hline
\end{tabular}

The results of univariate analyses for the association between study variables and the presence of high autoPEEP levels ( $\left.\geq 5 \mathrm{~cm} \mathrm{H}_{2} \mathrm{O}\right)$ are shown in Table 3, whereas the adjusted results from the multivariate logistic regression are shown in Table 4 . flow limitation and short $\mathrm{T}_{\mathrm{E}} / \tau_{\mathrm{RS}}$ were the strongest risk factors independently associated with high auto-PEEP, with adjusted odds ratios of 17 (95\% CI: 6-56.2) and 12.6 (95\% CI: 4.7-39.6), respectively. High $\mathrm{R}_{\mathrm{RS}}$, aging, and overweight were also associated with the risk of developing high auto-PEEP. 


\section{Assessment of Factors Related to Auto-PEEP}

Table 3. Univariate Analyses: Comparison Between Subjects With Low and High Auto-PEEP Values

\begin{tabular}{|c|c|c|c|}
\hline & Low Auto-PEEP $(n=81)$ & High Auto-PEEP $(n=105)$ & $P$ \\
\hline Auto-PEEP, $\mathrm{cm} \mathrm{H}_{2} \mathrm{O}$ & $3(2-3)$ & $6(5-8)$ & $<.001$ \\
\hline Age, y & $69(54-75)$ & $72(66-78)$ & .002 \\
\hline Elderly (>65 y), $n(\%)$ & $28(35)$ & $82(80)$ & $<.001$ \\
\hline Female sex, $n(\%)$ & $21(26)$ & $42(40)$ & .06 \\
\hline History of smoking, $n(\%)$ & $31(46)$ & $51(51)$ & .64 \\
\hline Chronic pulmonary disease, $n(\%)$ & $16(21)$ & $48(46)$ & $<.001$ \\
\hline Hypercapnic respiratory failure, $n(\%)$ & $16(20)$ & $32(31)$ & .13 \\
\hline Supine position, $n(\%)$ & $39(48)$ & $58(55)$ & .42 \\
\hline Flow limitation, $n(\%)$ & $12(15)$ & $63(60)$ & $<.001$ \\
\hline Tidal volume/kg IBW, mL/kg & $8(7-8)$ & $8(7-9)$ & .08 \\
\hline High tidal volume ( $>8 \mathrm{~mL} / \mathrm{kg}$ IBW), $n(\%)$ & $20(34)$ & $50(48)$ & .1 \\
\hline Breathing frequency, breaths/min & $20(16-20)$ & $20(16-22)$ & .26 \\
\hline Expiratory time, s & $1.63(1.33-2.35)$ & $1.61(1.33-2.49)$ & .75 \\
\hline Minute ventilation, $\mathrm{L} / \mathrm{min}$ & $9.5(1.9)$ & $9.7(2.4)$ & .53 \\
\hline Body mass index, $\mathrm{kg} / \mathrm{min}$ & $25(24-28)$ & $28(25-31)$ & .001 \\
\hline Overweight $(\mathrm{BMI}>26), n(\%)$ & $32(40)$ & $71(68)$ & $<.001$ \\
\hline $\mathrm{R}_{\mathrm{RS}}, \mathrm{cm} \mathrm{H} \mathrm{H}_{2} \mathrm{O} / \mathrm{L} / \mathrm{s}$ & $14(12-16)$ & $18(15-23)$ & $<.001$ \\
\hline $\operatorname{High} \mathrm{R}_{\mathrm{RS}}\left(\geq 15 \mathrm{~cm} \mathrm{H}_{2} \mathrm{O} / \mathrm{L} / \mathrm{s}\right), n(\%)$ & $28(35)$ & $82(80)$ & $<.001$ \\
\hline $\mathrm{C}_{\mathrm{RS}}, \mathrm{mL} / \mathrm{cm} \mathrm{H} \mathrm{H}_{2} \mathrm{O}$ & $59(50-71)$ & $56(43-67)$ & .12 \\
\hline Expiratory time/time constant & $2.11(1.57-2.81)$ & $1.73(1.25-2.36)$ & .001 \\
\hline Short expiratory time/time constant $(<1.85), n(\%)$ & $24(30)$ & $57(56)$ & $<.001$ \\
\hline $\mathrm{P}_{\mathrm{aO}_{2}} / \mathrm{F}_{\mathrm{IO}_{2}}, \mathrm{~mm} \mathrm{Hg}$ & $252(209-362)$ & $218(158-300)$ & .005 \\
\hline Low $\mathrm{P}_{\mathrm{aO}_{2}} / \mathrm{F}_{\mathrm{IO}_{2}}(<220), n(\%)$ & $23(29)$ & $55(52)$ & .002 \\
\hline $\begin{array}{l}\text { Data are shown as median (interquartile range) or } n(\%) . \\
\text { IBW }=\text { ideal body weight } \\
\text { BMI }=\text { body mass index } \\
\mathrm{R}_{\mathrm{RS}}=\text { resistance of the respiratory system } \\
\mathrm{C}_{\mathrm{RS}}=\text { compliance of the respiratory system }\end{array}$ & & & \\
\hline
\end{tabular}

Table 4. Multiple Logistic Regression: Adjusted Associations Between Study Variables and High Auto-PEEP

\begin{tabular}{lcc}
\hline \hline & Adjusted OR (95\% CI) & $P$ \\
\hline Flow limitation & $17(6-56.2)$ & $<.001$ \\
$\begin{array}{l}\text { Short expiratory time/time constant } \\
\quad(<1.85)\end{array}$ & $12.6(4.7-39.6)$ & $<.001$ \\
High $\mathrm{R}_{\mathrm{RS}}\left(\geq 15 \mathrm{~cm} \mathrm{H} \mathrm{H}_{2} \mathrm{O} / \mathrm{L} / \mathrm{s}\right)$ & $3(1.3-6.9)$ & .008 \\
Elderly $($ age $>65 \mathrm{y})$ & $2.8(1.2-6.5)$ & .02 \\
Overweight $\left(\mathrm{BMI}>26 \mathrm{~kg} / \mathrm{m}^{2}\right)$ & $2.6(1.1-6.1)$ & .03 \\
& & \\
OR = odds ratio & & \\
$\mathrm{R}_{\mathrm{RS}}=$ resistance of the respiratory system & & \\
BMI = body mass index & & \\
\hline
\end{tabular}

\section{Discussion}

Our data showed that flow limitation, $\mathrm{R}_{\mathrm{RS}}$, and $\mathrm{BMI}$ contributed to increase auto-PEEP, whereas $\mathrm{T}_{\mathrm{E}} / \tau_{\mathrm{RS}}$ reduced auto-PEEP. Categorical variables that were associated with high auto-PEEP levels were flow limitation, low $\mathrm{T}_{\mathrm{E}}$ relative to $\tau_{\mathrm{RS}}$, obesity, a high resistive profile, and aging.

Previous physiological studies have identified factors that are involved in auto-PEEP generation and the effect of
auto-PEEP on cardiorespiratory function. ${ }^{1-13}$ In our study, we investigated auto-PEEP from an epidemiological point of view and examined how much, and not how, auto-PEEP is associated with factors that are involved in the development of auto-PEEP. Surprisingly, we observed that in our sample of mechanically ventilated subjects, the variables that characterized the breathing pattern $\left(\mathrm{f}, \mathrm{T}_{\mathrm{E}}, \mathrm{V}_{\mathrm{T}}\right.$, and minute ventilation) appeared to have a marginal role in auto-PEEP in the absence of predisposing factors of the subjects (flow limitation, $\tau_{\mathrm{RS}}, \mathrm{R}_{\mathrm{RS}}$, $\mathrm{BMI}$, and aging). This result has clinical implications. Auto-PEEP can be more effectively reduced by acting primarily on modifiable characteristics of the patient, whereas manipulation of the breathing pattern might only have a negligible effect on the overall auto-PEEP value.

Flow limitation was the most important factor affecting the amount of auto-PEEP. This finding is consistent with observations by Armaganidis et al, ${ }^{13}$ who showed that in 12 subjects with flow limitation, auto-PEEP was higher than in 20 subjects without flow limitation. We speculated that because flow limitation can be effectively reduced by bronchodilators and the sitting position, ${ }^{19-21}$ these could be the most effective therapies for reducing auto-PEEP. More- 


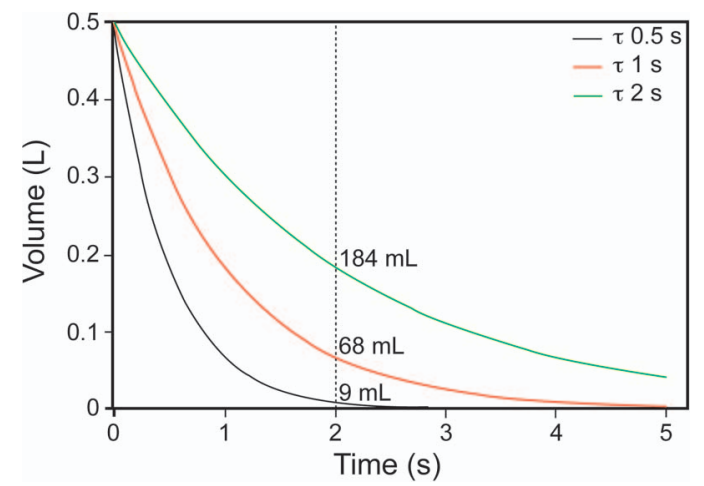

Fig. 1. Theoretical decrease of lung volume during passive expiration when the respiratory system's time constant, $\tau_{\mathrm{RS}}$, is $0.5,1$, and $2 \mathrm{~s}$. The vertical line intersects the curves after $2 \mathrm{~s}$ of expiration, and the respective unexpired volume is reported near each curve.

over, bronchodilators and corticosteroids ${ }^{22}$ can decrease auto-PEEP by reducing airway resistance and $\tau_{\mathrm{RS}}$. Bronchodilator therapy probably has a major role in reducing auto-PEEP.

$\mathrm{T}_{\mathrm{E}}$ by itself was unrelated to auto-PEEP, whereas $\mathrm{T}_{\mathrm{E}} / \tau_{\mathrm{RS}}$ was the second most important cause. This finding indicates that in patients with auto-PEEP, determining the duration of expiration should be addressed by considering the duration in terms of $\tau_{\mathrm{RS}}$ and not in seconds. Therefore, the proper unit of measurement of $\mathrm{T}_{\mathrm{E}}$ should not be seconds, but rather $\tau_{\mathrm{RS}}$; this implies that in patients with long $\tau_{\mathrm{RS}}$, only a substantial increase of $\mathrm{T}_{\mathrm{E}}$ (ie, proportional to $\tau_{\mathrm{RS}}$ ) can effectively reduce auto-PEEP. $\mathrm{T}_{\mathrm{E}} / \tau_{\mathrm{RS}}$ has a central role during physiological expiration because lung emptying is described by the equation: $\mathrm{V}_{(\mathrm{t})}=\mathrm{V}_{(0)} \times \mathrm{e}^{-\mathrm{t} / \tau}$, where $\mathrm{V}_{(0)}$ and $\mathrm{V}_{(\mathrm{t})}$ are the lung volume (above the relaxation volume of the respiratory system) at the start and at time $t$ from the onset of expiration, respectively. ${ }^{14,23}$ At end expiration, $t$ coincides with $\mathrm{T}_{\mathrm{E}}$, and the exponent of the above described equation becomes $-\mathrm{T}_{\mathrm{E}} / \tau_{\mathrm{RS}}$, which is the unique variable that determines an increase in endexpiratory lung volume above the relaxation volume (ie, dynamic hyperinflation). As an example of clinical implication of the equation, Figure 1 shows the decrease of lung volume over time during an expiration (ie, $\mathrm{V}_{(\mathrm{t})}$ ) in three hypothetical subjects with different $\tau_{\mathrm{RS}}(0.5,1$, and $2 \mathrm{~s})$ with the same initial starting volume, $\mathrm{V}_{(0)}$, at 0.51 . After $2 \mathrm{~s}$ of expiration (vertical line), a subject with $\tau_{\mathrm{RS}}$ of $0.5 \mathrm{~s}$ (dotted curve) would have almost completed the expiration, whereas at the same time, the unexpired volume would be $69 \mathrm{~mL}$ with a $\tau_{\mathrm{RS}}$ of $1 \mathrm{~s}$ (continuous curve) and $184 \mathrm{~mL}$ with a $\tau_{\mathrm{RS}}$ of $2 \mathrm{~s}$ (dashed curve). This shows how the same expiratory time has a substantially different effect on expired volume, depending on $\tau_{\mathrm{RS}}$. If $\mathrm{T}_{\mathrm{E}}$ were $2 \mathrm{~s}, \mathrm{~T}_{\mathrm{E}} / \tau_{\mathrm{RS}}$ would be 4 with $\tau_{\mathrm{RS}}=0.5 \mathrm{~s}, 2$ with $\tau_{\mathrm{RS}}=1 \mathrm{~s}$, and 1 with $\tau_{\mathrm{RS}}=2 \mathrm{~s}$. This also means that the 3 hypothetical subjects would require different values of $\mathrm{T}_{\mathrm{E}}$ to obtain $\mathrm{T}_{\mathrm{E}} / \tau_{\mathrm{RS}}<1.85$ and therefore to reduce the risk of high auto-PEEP (see Table 4).

We calculated $\tau_{\mathrm{RS}}$ by multiplying $\mathrm{C}_{\mathrm{RS}}$ by inspiratory $\mathrm{R}_{\mathrm{RS}} \cdot{ }^{14}$ Notably, in some clinical conditions (eg, in chronic obstructive pulmonary disease patients), the actual value of airway resistance could be slightly higher during expiration than during inspiration. ${ }^{24,25}$ Consequently, we could have underestimated $\tau_{\mathrm{RS}}$ and slightly overestimated the $\mathrm{T}_{\mathrm{E}} / \tau_{\mathrm{RS}}$ threshold associated with a high level of auto-PEEP.

The strong association between auto-PEEP and the $\mathrm{T}_{\mathrm{E}} / \tau_{\mathrm{RS}}$ ratio, but no association between auto-PEEP and $\mathrm{V}_{\mathrm{T}}$, could have clinical implications. A reduction in $\mathrm{V}_{\mathrm{T}}$ and increase in $T_{E}$ have been advocated as a strategy to decrease dynamic hyperinflation in obstructive patients. ${ }^{1,9}$ However, in some instances, carrying out both options could be unpractical because of the risk of severe hypoventilation. Our results suggest that in those cases, autoPEEP could be more effectively reduced by increasing $T_{E}$ (ie, increasing inspiratory flow or reducing breathing frequency) to increase $\mathrm{T}_{\mathrm{E}} / \tau_{\mathrm{RS}}$ than by decreasing $\mathrm{V}_{\mathrm{T}}$.

Theoretically, dynamic hyperinflation rises when $R_{R S}$ or $\mathrm{C}_{\mathrm{RS}}$ increases, ${ }^{1,8}$ but in our models, only $\mathrm{R}_{\mathrm{RS}}$ had an effect on auto-PEEP. This can be explained by considering that the reduced elastic recoil related to high $\mathrm{C}_{\mathrm{RS}}$ favors dynamic hyperinflation because of the reduction in expiratory flow. Nevertheless, at the same time, high $\mathrm{C}_{\mathrm{RS}}$ limits pressurization of trapped gas, thus restraining the autoPEEP level. Our data are consistent with this interpretation. When we substituted auto-PEEP with dynamic hyperinflation (calculated as auto-PEEP $\times \mathrm{C}_{\mathrm{RS}}$ ) as a dependent variable in our linear model, $\mathrm{C}_{\mathrm{RS}}$ became strongly related to dynamic hyperinflation. Moreover, in this new model, flow limitation, $\mathrm{R}_{\mathrm{RS}}, \mathrm{T}_{\mathrm{E}} / \tau_{\mathrm{RS}}$, and $\mathrm{BMI}$ maintained their relationship consistently with the model with auto-PEEP as a dependent variable.

In our study, aging and obesity were also associated with an increased risk of high auto-PEEP. Accordingly, we speculate that auto-PEEP should not usually be a clinically relevant issue in young and/or underweight to normal weight patients, whereas high auto-PEEP levels should be considered as more probable in aged and/or overweight patients.

Auto-PEEP measurements can be difficult and challenging in patients with spontaneous respiratory activity because of the contribution of expiratory muscle activity. ${ }^{25}$ Therefore, our findings could help to estimate high autoPEEP $\left(\geq 5 \mathrm{~cm} \mathrm{H}_{2} \mathrm{O}\right.$ ) in actively breathing patients when auto-PEEP measurements are unreliable. In particular, the diagnosis of flow limitation could help to identify patients with high auto-PEEP levels at the bedside because of the high risk of flow-limited patients and the reliability of the manual compression of the abdominal maneuver. The diagnosis of flow limitation with the manual compression of 
the abdominal maneuver is simple, does not require any device (apart from the availability of the flow-volume loop), and has been validated in spontaneously breathing subjects and in sedated mechanically ventilated subjects. ${ }^{15-17}$

We measured auto-PEEP after a reasonably long endexpiratory pause (4 min) in order to reach an unambiguously stable value of auto-PEEP when trapped gas gradually decompresses into the central airways. ${ }^{1}$ Therefore, auto-PEEP measurements should be reliable even in patients with severe inhomogeneous lung disease and long time constants.

Our study was conducted on passive subjects during controlled mechanical ventilation to allow reliable measurement of total PEEP. This choice is both a strength and a limitation of the study. Measurement of auto-PEEP in actively breathing patients is challenging. 25,26 The choice to enroll only subjects with passive expiration guaranteed that all measurements were accurate and reproducible. However, our results should be generalized with caution in actively breathing patients, even if the breathing pattern of the subjects in our study is similar to that of patients with acute respiratory failure of different etiologies during assisted ventilation. ${ }^{7,26,27} \mathrm{We}$ cannot exclude the possibility that the activity of expiratory muscles could modify the findings of our study. In subjects without flow limitation, total PEEP could be decreased by active expiration, and hyperinflation could be actively limited with increased effort of the expiratory muscles.

\section{Conclusions}

In subjects with dynamic hyperinflation, the amount of auto-PEEP mainly depends on flow limitation, a long $\tau_{\mathrm{RS}}$ compared with available expiratory time, high $\mathrm{R}_{\mathrm{RS}}$, and overweight. Therapeutic strategies aimed at reducing autoPEEP and its adverse effects should be primarily oriented to these targets.

\section{VENTILAB Group Investigators}

Fondazione Poliaambulanza Hospital, Brescia, Italy: Giuseppe Natalini MD, Antonio Rosano MD, Michele Grazioli MD, Achille Bernardini MD, Anna Granato MD, Department of Anesthesia and Intensive Care.

Spedali Civili Hospital, Brescia, Italy: Daniele Tuzzo MD, Gabriele Tomasoni MD, Department of Anesthesia and Intensive Care.

SS Annunziata Hospital, Savigliano, Italy: Marco Testa MD, Irene Iannaco MD, Department of Anesthesia and Intensive Care.

Misericordia Hospital, Grosseto, Italy: Vincenzo Pennestrì MD, Department of Anesthesia and Intensive Care.

San Giovanni Bosco Hospital, Napoli, Italy: Guido Amodeo MD, Antonella Ferrari MD, Department of Anesthesia and Intensive Care.
Cardarelli Hospital, Napoli, Italy: Paolo F Marsilia MD, Maria Alfieri MD, Maria Giovanna de Cristofaro MD, Luigi Mendetta MD, Department of Anesthesia and Intensive Care.

Mellino Mellini Hospital, Chiari, Italy: Andrea Tinnirello MD, Giovanni Amicucci MD, Manuel Todeschini MD, Department of Anesthesia and Intensive Care.

Agnelli Hospital, Pinerolo, Italy: Francesco Berruto MD, Department of Anesthesia and Intensive Care.

Santa Maria degli Angeli Hospital, Pordenone, Italy: Marialinda Fiorillo MD, Department of Anesthesia and Intensive Care.

University of Brescia at Spedali Civili, Brescia, Italy: Matteo Filippini MD, Filippo Albani MD, Michele Bertoni MD, Barbara Buizza MD, Nicola Latronico MD, Sara Merelli MD, Ilaria Nodari MD, Laura Porcella MD, Mariarosa Tommasi MD, Maddalena Turin MD, Fabio Turla MD, Department of Anesthesia, Critical Care Medicine, and Emergency.

Cattinara Hospital, Trieste, Italy: Alberto Peratoner MD, Umberto Lucangelo MD, Department of Anesthesia and Intensive Care.

Imperial College, London, United Kingdom: Cosetta Minelli MD PhD, Respiratory Epidemiology, Occupational Medicine \& Public Health.

\section{REFERENCES}

1. Marini JJ. Dynamic hyperinflation and auto-positive end-expiratory pressure: lessons learned over 30 years. Am J Respir Crit Care Med 2011;184(7):756-762.

2. Pepe PE, Marini JJ. Occult positive end-expiratory pressure in mechanically ventilated patients with airflow obstruction: the auto-PEEP effect. Am Rev Respir Dis 1982;126(1):166-170.

3. Smith TC, Marini JJ. Impact of PEEP on lung mechanics and work of breathing in severe airflow obstruction. J Appl Physiol 1988; 65(4):1488-1499.

4. Kawagoe Y, Permutt S, Fessler HE. Hyperinflation with intrinsic PEEP and respiratory muscle blood flow. J Appl Physiol 1994;77(5): 2440-2448.

5. Leung P, Jubran A, Tobin MJ. Comparison of assisted ventilator modes on triggering, patient effort, and dyspnea. Am J Respir Crit Care Med 1997;155(6):1940-1948.

6. Laghi F, Tobin MJ. Disorders of the respiratory muscles. Am J Respir Crit Care Med 2003;168(1):10-48.

7. Thille AW, Cabello B, Galia F, Lyazidi A, Brochard L. Reduction of patient-ventilator asynchrony by reducing tidal volume during pressure-support ventilation. Intensive Care Med 2008;34(8):1477-1486.

8. Laghi F, Goyal A. Auto-PEEP in respiratory failure. Minerva Anestesiol 2012;78(2):201-221.

9. Tuxen DV, Lane S. The effects of ventilatory pattern on hyperinflation, airway pressures, and circulation in mechanical ventilation of patients with severe air-flow obstruction. Am Rev Respir Dis 1987; 136(4):872-879.

10. Bernasconi M, Ploysongsang Y, Gottfried SB, Milic-Emili J, Rossi A. Respiratory compliance and resistance in mechanically ventilated patients with acute respiratory failure. Intensive Care Med 1988; 14(5):547-553. 


\section{Assessment of Factors Related to Auto-PEEP}

11. Marini JJ, Crooke PS. A general mathematical model for respiratory dynamics relevant to the clinical setting. Am Rev Respir Dis 1993; 147(1):14-24

12. Kacmarek RM, Kirmse M, Nishimura M, Mang H, Kimball WR. The effects of applied vs auto-PEEP on local lung unit pressure and volume in a four-unit lung model. Chest 1995;108(4):1073-1079.

13. Armaganidis A, Stavrakaki-Kallergi K, Koutsoukou A, Lymberis A, Milic-Emili J, Roussos C. Intrinsic positive end-expiratory pressure in mechanically ventilated patients with and without tidal expiratory flow limitation. Crit Care Med 2000;28(12):3837-3842.

14. Zin WA, Pengelly LD, Milic-Emili J. Single-breath method for measurement of respiratory mechanics in anesthetized animals. J Appl Physiol 1982;52(5):1266-1271.

15. Ninane V, Leduc D, Kafi SA, Nasser M, Houa M, Sergysels R. Detection of expiratory flow limitation by manual compression of the abdominal wall. Am J Respir Crit Care Med 2001;163(6):13261330 .

16. Abdel Kafi S, Sersté T, Leduc D, Sergysels R, Ninane V. Expiratory flow limitation during exercise in COPD: detection by manual compression of the abdominal wall. Eur Respir J 2002;19(5):919-927.

17. Lemyze M, Favory R, Alves I, Perez T, Mathieu D. Manual compression of the abdomen to assess expiratory flow limitation during mechanical ventilation. J Crit Care 2012;27(1):37-44.

18. Peduzzi P, Concato J, Kemper E, Holford TR, Feinstein AR. A simulation study of the number of events per variable in logistic regression analysis. J Clin Epidemiol 1996;49(12):1373-1379.

19. Tantucci C, Duguet A, Similowski T, Zelter M, Derenne J-P, MilicEmili J. Effect of salbutamol on dynamic hyperinflation in chronic obstructive pulmonary disease patients. Eur Respir J 1998;12(4): 799-804.

20. Boni E, Corda L, Franchini D, Chiroli P, Damiani GP, Pini L, et al. Volume effect and exertional dyspnoea after bronchodilator in patients with COPD with and without expiratory flow limitation at rest. Thorax 2002;57(6):528-532.
21. Lemyze M, Mallat J, Duhamel A, Pepy F, Gasan G, Barrailler S, et al. Effects of sitting position and applied positive end-expiratory pressure on respiratory mechanics of critically ill obese patients receiving mechanical ventilation. Crit Care Med 2013;41(11):25922599.

22. Rubini F, Rampulla C, Nava S. Acute effect of corticosteroids on respiratory mechanics in mechanically ventilated patients with chronic airflow obstruction and acute respiratory failure. Am J Respir Crit Care Med 1994;149(2):306-310.

23. Lumb AB. Mathematical functions relevant to respiratory physiology. In: Nunn's applied respiratory physiology, 7th edition. Edinburgh: Churchill Livingstone Elsevier Ltd; 2010:521-528.

24. Paredi P, Goldman M, Alamen A, Ausin P, Usmani OS, Pride NB, Barnes PJ. Comparison of inspiratory and expiratory resistance and reactance in patients with asthma and chronic obstructive pulmonary disease. Thorax 2010;65(3):263-267.

25. Yamauchi $Y$, Kohyama T, Jo T, Nagase T. Dynamic change in respiratory resistance during inspiratory and expiratory phases of tidal breathing in patients with chronic obstructive pulmonary disease. Int J Chron Obstruct Pulmon Dis 2012;7:259-269.

25. Zakynthinos SG, Vassilakopoulos T, Zakynthinos E, Mavrommatis A, Roussos C. Contribution of expiratory muscle pressure to dynamic intrinsic positive end-expiratory pressure: validation using the Campbell diagram. Am J Respir Crit Care Med 2000;162(5):16331640.

26. Nava S, Bruschi C, Fracchia C, Braschi A, Rubini F. Patient-ventilator interaction and inspiratory effort during pressure support ventilation in patients with different pathologies. Eur Respir J 1997; 10(1):177-183.

27. Vitacca M, Bianchi L, Zanotti E, Vianello A, Barbano L, Porta R, Clini E. Assessment of physiologic variables and subjective comfort under different levels of pressure support ventilation. Chest 2004;126(3):851-859.

This article is approved for Continuing Respiratory Care Education credit. For information and to obtain your CRCE

(free to AARC members) visit

www.rcjournal.com

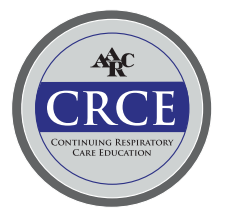

